\title{
Synthesis, Crystal Structure, and Catalytic Activity of a Calcuim(II) Complex with 4-Formylbenzene-1,3- disulfonate-isonicotinic Acid Hydrazone
}

\author{
Xi-Shi Tai ${ }^{*}$, Peng-Fei Li ${ }^{2}$, Li-Li Liu ${ }^{1}$ \\ ${ }^{1}$ College of Chemistry and Chemical Engineering, Weifang University, Weifang 261061, P.R. China \\ ${ }^{2}$ College of Chemical Engineering, Qingdao University of Science and Technology, \\ Qingdao 266061, P.R. China
}

Received: $13^{\text {rd }}$ December 2017; Revised: $23^{\text {rd }}$ May 2018; Accepted: $23^{\text {rd }}$ May 2018; Available online: $14^{\text {th }}$ November 2018; Published regularly: December 2018

\begin{abstract}
A new calcium(II) complex was synthesized by one-pot synthesis method from disodium 4 -formylbenzene-1,3-disulfonate, isonicotinic acid hydrazide and $\mathrm{Ca}\left(\mathrm{ClO}_{4}\right)_{2} \cdot 2 \mathrm{H}_{2} \mathrm{O}$. The structure of calcium(II) complex was determined by elemental analysis, IR and single crystal X-ray diffraction. The results show that the $\mathrm{Ca}(\mathrm{II})$ complex molecules form 3D network structure by the interactions of $\Pi-\Pi$ stacking and hydrogen bonds. The $\mathrm{Ca}$ (II) complex catalyst could efficiently catalyse oxidation of benzylic alcohol with good conversion of benzyl alcohol (78\%) and excellent selectivity of benzaldehyde (98 \%). Copyright (C) 2018 BCREC Group. All rights reserved.
\end{abstract}

Keywords: Ca(II) Complex Catalyst; Synthesis; Structural Characterization; Catalytic Activity

How to Cite: Tai, X.S., Li, P.F., Liu, L.L. (2018). Synthesis, Crystal Structure, and Catalytic Activity of a Calcium(II) Complex with 4-Formylbenzene-1,3-disulfonate-isonicotinic Acid Hydrazone. Bulletin of Chemical Reaction Engineering \& Catalysis, 13 (3): 429-435 (doi:10.9767/bcrec.13.3.1961.429-435)

Permalink/DOI: https://doi.org/10.9767/bcrec.13.3.1961.429-435

\section{Introduction}

The design and synthesis of metal-organic complex catalytic materials have been one of the most interesting researches in the materials chemistry [1-3]. Because they show outstanding catalytic activities for many organic reactions such as $\mathrm{CO}_{2}$ cycloaddition [4,5], $\mathrm{CO}_{2}$ coupling [6], degradation of organic dyes [7], $\mathrm{A}^{3}$ coupling reaction $[8,9]$, iso-selective ring opening [1012], cross-aldol condensation [13], knoevenagel condensation [14-19], tandem reaction [20], and so on. Benzaldehyde is an important intermediate of organic synthesis and fine chemical

* Corresponding Author.

E-mail: taixs@wfu.edu.cn (Tai, X.S.)

Telp: +86-536-8785363, Fax: +86-536-8785363 products, widely used in medicine, dyes, spices, resins, and other industries. However, the benzaldehyde was prepared by oxidation of benzyl alcohol with toxic metal oxides, peroxides, halides, and so on [21-23]. So, the development of environmentally friendly catalysts is very attractive. We have been devoted to the study on synthesis, structure and catalytic property of metal complexes [24-27]. In this paper, a new calcium (II) complex was synthesized by one-pot synthesis method from disodium 4-formylbenzene-1,3-disulfonate, isonicotinic acid hydrazide and $\mathrm{Ca}\left(\mathrm{ClO}_{4}\right)_{2} \cdot 2 \mathrm{H}_{2} \mathrm{O}$. The $\mathrm{Ca}$ (II) complex catalyst could efficiently catalyze oxidation of benzylic alcohol with good conversion of benzyl alcohol and excellent selectivity of benzaldehyde. 


\section{Materials and Method}

\subsection{Materials and Equipments}

Disodium 4-formylbenzene-1,3-disulfonate, isonicotinic acid hydrazide and $\mathrm{Ca}\left(\mathrm{ClO}_{4}\right)_{2} \cdot 2 \mathrm{H}_{2} \mathrm{O}$ were supplied by Aldrich. Elemental analysis was carried out on a Elemental Vario EL-III elemental analyzer. IR (4000-400 $\left.\mathrm{cm}^{-1}\right)$ was obtained with a Nicolet Nexus 670 FTIR spectrophotometer. The crystal structure of calcium(II) complex was analyzed using a Bruker Amart CCD diffractometer.

\subsection{Synthesis of $\mathrm{Ca}(\mathrm{II})$ Complex}

Disodium 4-formylbenzene-1,3-disulfonate $(0.1551 \mathrm{~g}, \quad 0.5 \mathrm{mmol})$, isonicotinic acid hydrazide $\quad(0.6852 \mathrm{~g}, \quad 0.5 \mathrm{mmol})$ and $\mathrm{Ca}\left(\mathrm{ClO}_{4}\right)_{2} \cdot 2 \mathrm{H}_{2} \mathrm{O}(0.110 \mathrm{~g}, 0.5 \mathrm{mmol})$ were dissolved in $15 \mathrm{~mL}$ ethanol/water (v:v $=2: 1)$ solution. The above mixture was heated to $65^{\circ} \mathrm{C}$ for $6 \mathrm{~h}$ with stirring. After cooled, the solution was filtered and the colorless block crystals were obtained by slowly evaporating the filtrate at room temperature. Yield: $61 \%$. IR u/ $\mathrm{cm}^{-1}: 3445$ $\mathrm{cm}^{-1}$ (O-H stretch), $1656 \mathrm{~cm}^{-1}(\mathrm{C}=\mathrm{N}), 1227 \mathrm{~cm}^{-1}$ $\left.\left(\mathrm{SO}_{3}\right)^{-}\right)$, and $1165 \mathrm{~cm}^{-1}\left(\mathrm{SO}_{3}\right)^{-}$. Anal. Calc. for $\mathrm{C}_{26} \mathrm{H}_{42} \mathrm{Ca}_{2} \mathrm{~N}_{6} \mathrm{O}_{26} \mathrm{~S}_{4}:$ C, $29.35 \%$; H, $3.95 \%$; N, 7.90 \%. Found: C, $29.08 \%$; H, $4.26 \%$; N, 7.75 $\%$. The reaction equation for the formation of $\mathrm{Ca}$ (II) complex is shown in Figure 1.

\subsection{Crystal Structure Determination}

Single crystal data of $\mathrm{Ca}$ (II) complex was obtained from Bruker Smart Apex-II CCD area detector diffractometer by using $\mathrm{MoKa}$ radiation and $\varphi \sim \omega$ scan mode at 293 (2) K. The structure was solved by direct methods with SHELXS-97 [28] and refined by full-matrix

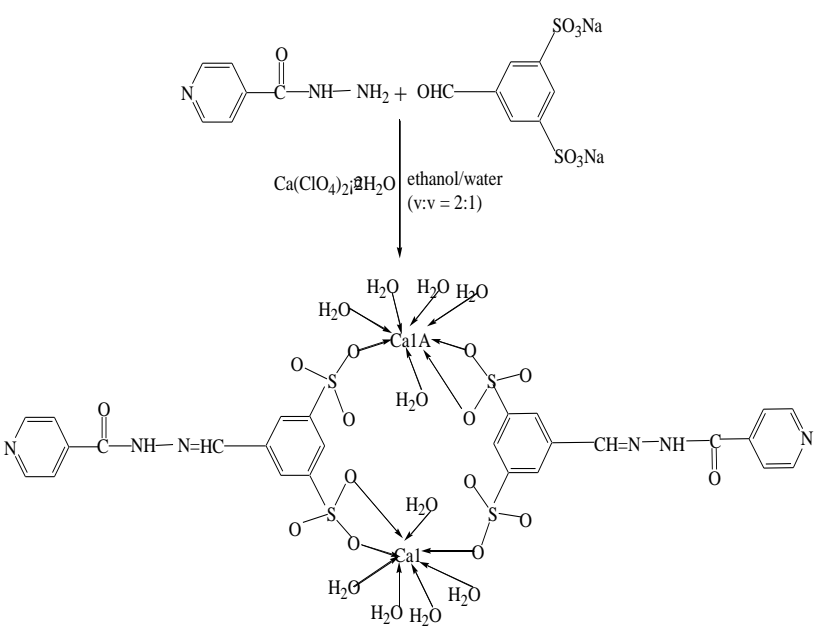

Figure 1. The reaction equation for the formation of $\mathrm{Ca}$ (II) complex least-squares techniques on $F^{2}$ with SHELXL [29]. The crystallographic data and refinement details for $\mathrm{Ca}$ (II) complex are listed in Table 1.

\subsection{Catalytic Test of Benzyl Alcohol Oxidation}

In a typical experiment, benzyl alcohol $(0.2$ mmol, $0.0216 \mathrm{~g})$, solvent (1.50 g), and catalyst $(0.060 \mathrm{~g})$ were added into a $10 \mathrm{~mL}$ stainless steel autoclave. After the reactor was sealed, the pure $\mathrm{O}_{2}$ was pumped to replace the atmosphere for six times. Then under pressure of 1 $\mathrm{MPa}$, the mixture was kept at $120-140{ }^{\circ} \mathrm{C}$ for 6 $h$ with vigorous stirring. After the reaction, the mixture was centrifuged to remove the catalyst. The conversion of benzyl alcohol and the selectivity of benzaldehyde were determined by gas chromatography equipped with a SE-54 capillary column $(\mathrm{GC}-1100,0.25 \mathrm{~mm} \times 0.25 \mathrm{~mm} \times$ $30 \mathrm{~m})$.

Table 1. Crystallographic data and refinement details for $\mathrm{Ca}(\mathrm{II})$ complex

\begin{tabular}{|c|c|}
\hline Empirical formula & $\mathrm{C}_{26} \mathrm{H}_{42} \mathrm{Ca}_{2} \mathrm{~N}_{6} \mathrm{O}_{26} \mathrm{~S}_{4}$ \\
\hline Formula weight & 1063.05 \\
\hline Temperature/K & $293(2)$ \\
\hline Crystal system & triclinic \\
\hline Space group & $P-1$ \\
\hline$a / \AA$ & 7.1961(14) \\
\hline$b / \AA$ & $11.972(2)$ \\
\hline$c / \AA$ & $12.275(3)$ \\
\hline$a /^{\circ}$ & $89.76(3)$ \\
\hline$\beta /^{\circ}$ & $88.09(3)$ \\
\hline$\gamma /{ }^{\circ}$ & $83.21(3)$ \\
\hline Volume/Å ${ }^{3}$ & $1049.5(4)$ \\
\hline$Z$ & 1 \\
\hline$\rho_{\text {calc }} \mathrm{mg} / \mathrm{mm}^{3}$ & 1.682 \\
\hline$\mu / \mathrm{mm}^{-1}$ & 0.571 \\
\hline$S$ & 1.048 \\
\hline$F(000)$ & 552 \\
\hline Index ranges & $\begin{array}{l}-8 \leq h \leq 9 \\
-15 \leq k \leq 15 \\
-15 \leq l \leq 15\end{array}$ \\
\hline Reflections collected & 10314 \\
\hline Independent reflections & $4771[R(\mathrm{int})=0.0228]$ \\
\hline Data/restraints/parameters & $4771 / 0 / 297$ \\
\hline Goodness-of-fit on $F^{2}$ & 1.085 \\
\hline Final $R$ indexes $[I \geq 2 \sigma(I)]$ & $R_{1}=0.0413, w R_{2}=0.1258$ \\
\hline Final $R$ indexes [all data] & $R_{1}=0.0452, w R_{2}=0.1187$ \\
\hline Largest diff. peak and hole & 0.837 and $-0.659 \mathrm{e} \cdot \AA^{-3}$ \\
\hline
\end{tabular}




\section{Results and Discussion}

\subsection{IR Spectra of $\mathrm{Ca}$ (II) Complex}

The IR spectrum (Figure 2) of $\mathrm{Ca}(\mathrm{II})$ complex shows the bands at $3445 \mathrm{~cm}^{-1}(\mathrm{O}-\mathrm{H}$ stretch), $\left.1656 \mathrm{~cm}^{-1}(\mathrm{C}=\mathrm{N}), 1227 \mathrm{~cm}^{-1}\left(\mathrm{SO}_{3}\right)^{-}\right)$, and $1165 \mathrm{~cm}^{-1}\left(\mathrm{SO}_{3}^{-}\right)$, respectively. The results of IR show that the $\mathrm{Ca}$ (II) complex contains $\mathrm{H}_{2} \mathrm{O}$ molecules and only the $\mathrm{O}$ atoms of $\mathrm{SO}_{3}$ - groups take part in coordination with $\mathrm{Ca}(\mathrm{II})$ ion by comparison with ref. [30]. The results are also confirmed by crystal structure analysis.

\subsection{Structural Description of Ca(II) Complex}

The $\mathrm{Ca}$ (II) complex crystallizes in the triclinic space group $P-1$. The detailed analysis of the crystal structure indicates that the $\mathrm{Ca}$ (II) complex is made up of two $\mathrm{Ca}(\mathrm{II})$ ions, two 4-formylbenzene-1,3-disulfonate-isonicotinic acid hydrazone ligands, ten coordinated water molecules and two lattice water molecules (Figure 3). Each $\mathrm{Ca}(\mathrm{II})$ ion is coordinated with

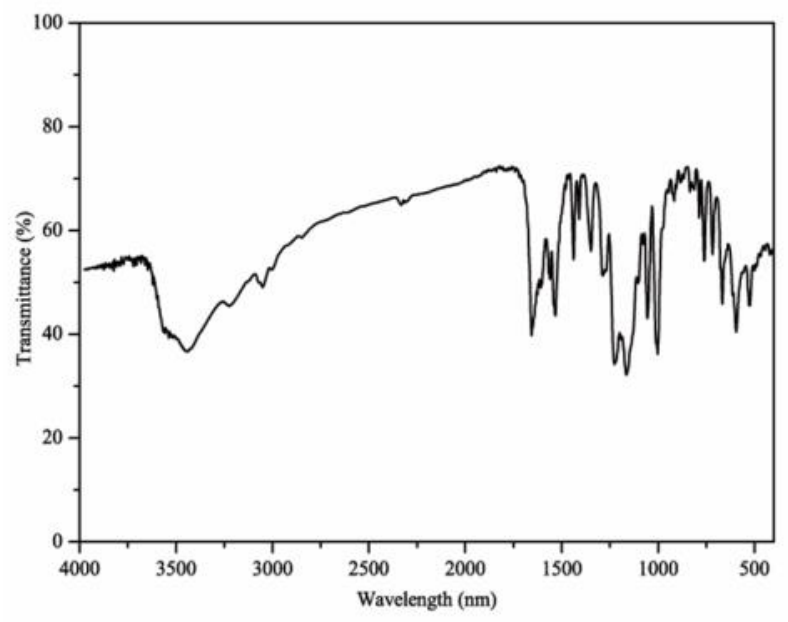

Figure 2. The IR spectrum of $\mathrm{Ca}(\mathrm{II})$ complex three $\mathrm{O}$ atoms of $\mathrm{SO}_{3}$ groups from two dif-ferent 4 -formylbenzene-1,3-disulfonateisonicotinic acid hydrazone ligands and five $\mathrm{O}$ atoms from five coordinated water molecules to form a distorted trigonal dodecahedron geometry. The dihedral angle between two rings (ring 1: C1-C2-C3-C4-C5-C6, ring 2: C9-C10-C11-N1$\mathrm{C} 12-\mathrm{C} 13)$ is $8.2^{\circ}$, indicating that the ligand is almost coplanar. The complex molecules form 1D chained structure by $\pi-\pi$ interactions (Figure 4), and further to form a threedimensional network structure (Figure 5). The important bond lengths and angles are given in Table 2.

\subsection{Catalytic Testing Studies}

The catalytic performance of the $\mathrm{Ca}$ (II) complex was assessed in the oxidation of benzyl alcohol. The equation of conversion of benzyl alcohol oxidation is shown in Figure 6. The results of the catalytic activity of the $\mathrm{Ca}$ (II) complex are given in Table 3. First, we investigated the effect of the solvent system on the efficiency and found that 1,4-dioxane is the best solvent for the benzyl alcohol oxidation reaction. As shown in Table 3, the conversion of benzyl alcohol and selectivity of benzaldehyde in 1,4-dioxane are $78 \%$ and $98 \%$ at $130{ }^{\circ} \mathrm{C}$ for $6 \mathrm{~h}$, respectively (Table 3, entry 1). Meanwhile, the corresponding conversion and selectivity in tetrahydrofuran were $57 \%$ and $61 \%$ at $130{ }^{\circ} \mathrm{C}$ for $6 \mathrm{~h}$, respectively (Table 3 , entry 2). However, the benzyl alcohol conversion and the benzaldehyde selectivity were $12 \%, 10 \%, 9 \%$ and $25 \%, 14 \%, 14 \%$ when dimethylformamide, acetonitrile, and ethyl acetate was used as solvent at $130{ }^{\circ} \mathrm{C}$ within $6 \mathrm{~h}$, respectively (Table 3, entry 3-5). In addition, the reaction temperature was investigated for the impact on the benzyl alcohol conversion and benzalde-

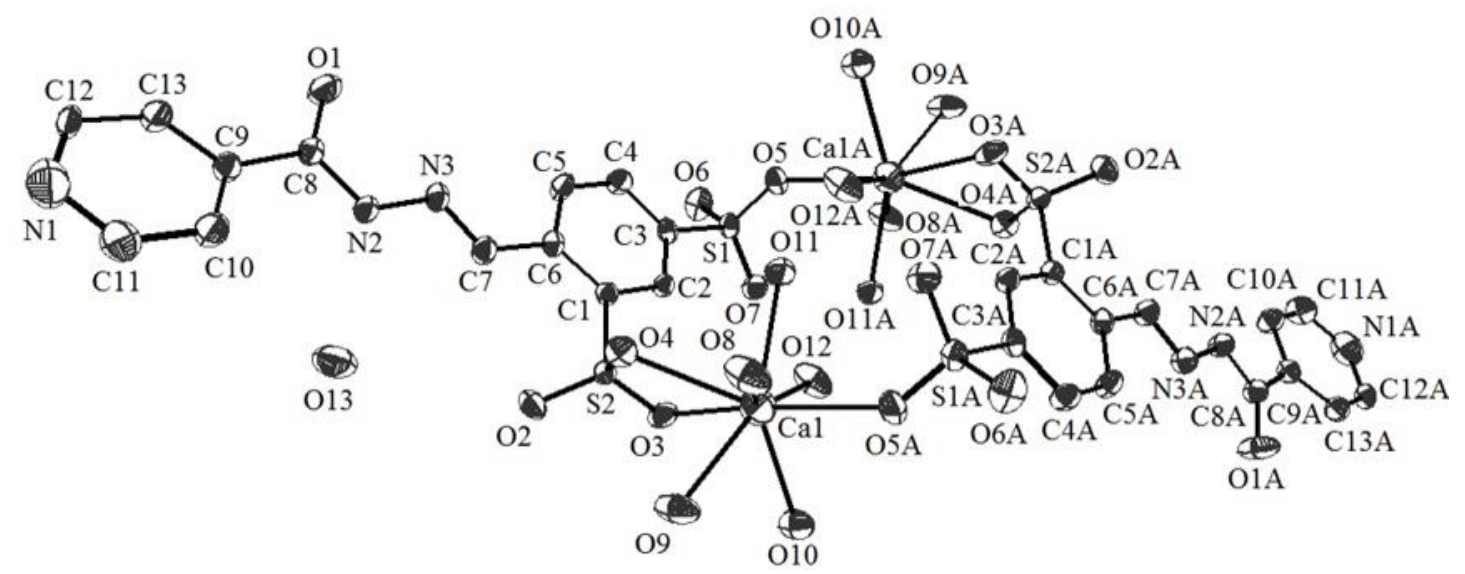

Figure 3. The molecular structure of $\mathrm{Ca}$ (II) complex 
hyde selectivity of the oxidation reactions. Upon increase the reaction temperature from 120 ${ }^{\circ} \mathrm{C}$ to $130{ }^{\circ} \mathrm{C}$ in 1,4 -dioxane, the conversion of benzyl alcohol dramatically enhanced (Table 3, entries 1 and 6). Notably, $98 \%$ selectivity toward benzaldehyde was maintained during the temperature increasing from $120^{\circ} \mathrm{C}$ to $130{ }^{\circ} \mathrm{C}$ (Table 3, entries 1 and 6). The conversion of benzyl alcohol and the selectivity of benzaldehyde were $80 \%$ and $67 \%$ at $140{ }^{\circ} \mathrm{C}$ for $6 \mathrm{~h}$ (Table 3, entry 7). The good conversion of benzyl alcohol (78 \%) and excellent selectivity of benzaldehyde (98\%) was achieved when the reaction was carried out at $130{ }^{\circ} \mathrm{C}$ in 1,4-dioxane. Therefore, it appears that $130{ }^{\circ} \mathrm{C}$ is the optimum temperature for the benzyl alcohol oxida- tion reaction over the complex. Based on the above results, the optimum conditions of the benzyl alcohol oxidation reaction over the $\mathrm{Ca}$ (II) complex catalyst are $130{ }^{\circ} \mathrm{C}, 1,4$-dioxane as solvent and $6 \mathrm{~h}$ (reaction time).

As the structure of $\mathrm{Ca}$ (II) complex (Figure 4 and Figure 5) shows, coordinatively unsaturated calcium is completely exposed to the pore of the $\mathrm{Ca}$ (II) complex. The coordinatively unsaturated calcium could be easily contact with the reactant (benzyl alcohol and $\mathrm{O}_{2}$ ) which is benefit to the catalytic reaction. In addition, it can also promote rapidly removal of the product (benzaldehyde), and prevent further reaction of the benzaldehyde. A possible mechanism for the selective benzyl alcohol oxidation over the

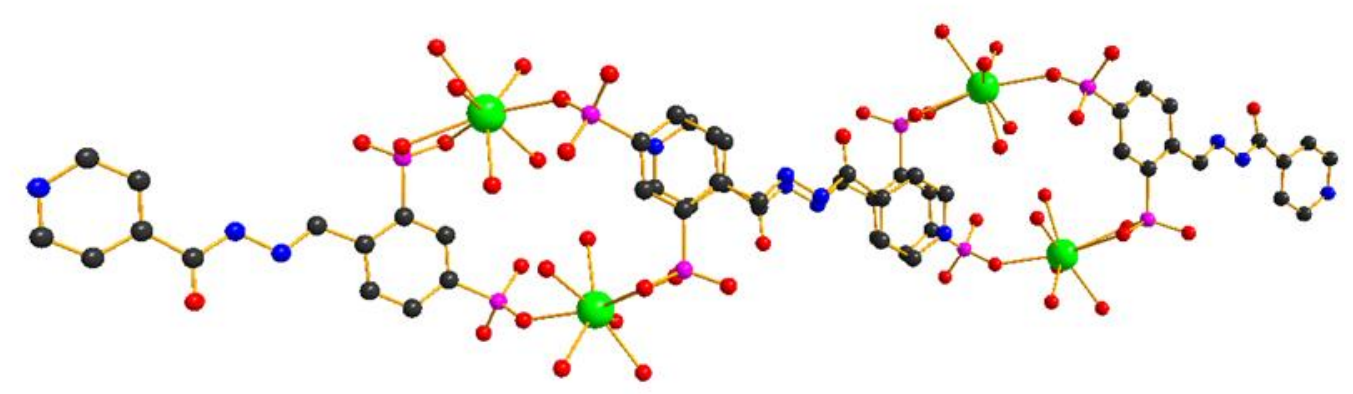

Figure 4. The 1D chained structure of $\mathrm{Ca}$ (II) complex

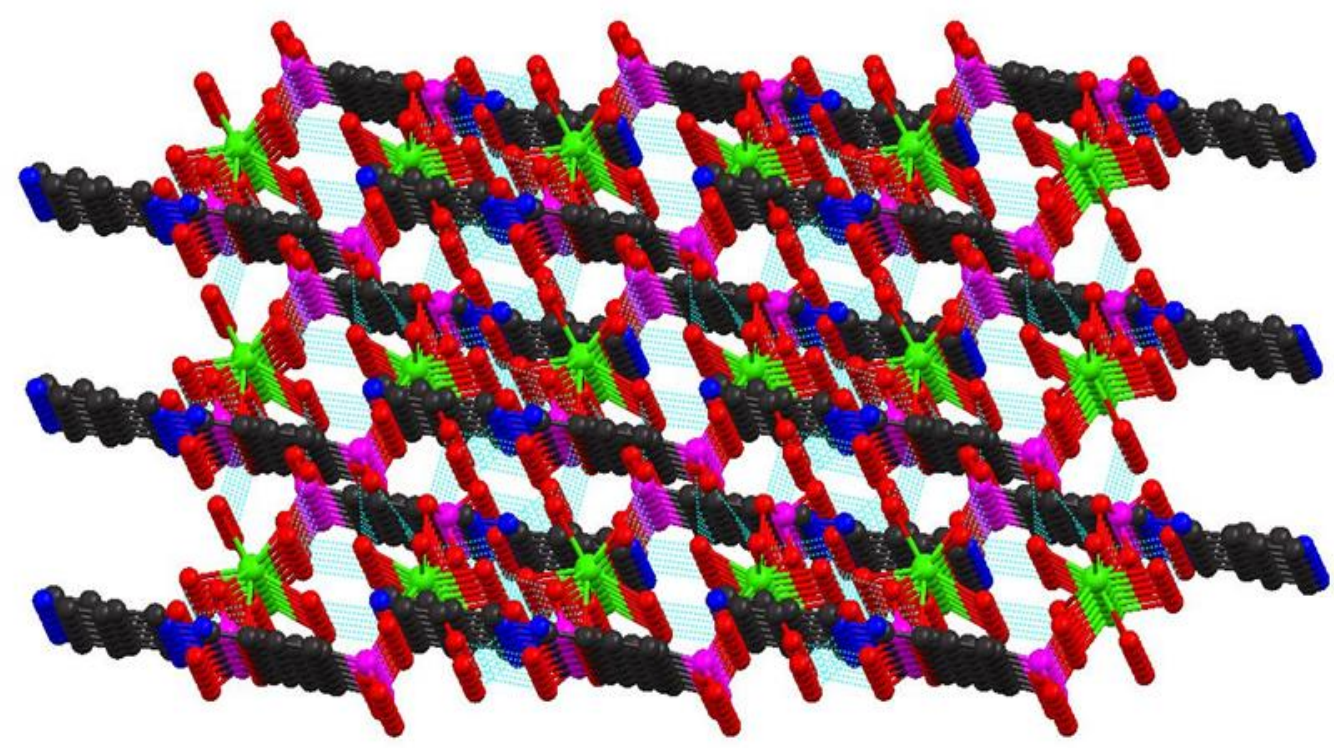

Figure 5. The 3D network structure of $\mathrm{Ca}(\mathrm{II})$ complex

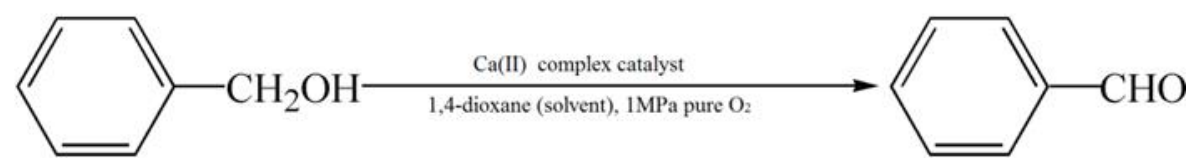

Figure 6. The conversion of benzyl alcohol oxidation 
Table 2. The important bond lengths and angles of $\mathrm{Ca}$ (II) complex

\begin{tabular}{|c|c|c|c|}
\hline Bond & Distance $(\AA)$ & Angle & $\left({ }^{\circ}\right)$ \\
\hline O3-Ca1 & $2.691(2)$ & O4-Ca1-O3 & $53.47(6)$ \\
\hline Ca1-O4 & $2.590(19)$ & O5-Ca1-O3 & $147.45(6)$ \\
\hline Ca1-O5 & $2.4302(19)$ & O4-Ca1-O5 & $153.35(6)$ \\
\hline Ca1-O8 & $2.486(2)$ & O5-Ca1-O8 & $78.46(7)$ \\
\hline Ca1-O9 & 2.3910(19) & O5-Ca1-O10 & $79.85(7)$ \\
\hline Ca1-O10 & 2.4481(19) & O5-Ca1-O11 & $80.70(6)$ \\
\hline $\mathrm{Ca} 1-\mathrm{O} 12$ & 2.4157(19) & O8-Ca1-O3 & $133.92(7)$ \\
\hline \multirow[t]{21}{*}{ Ca1-O11 } & 2.4309(19) & O8-Ca1-O4 & $82.06(7)$ \\
\hline & & O9-Ca1-O3 & $83.81(7)$ \\
\hline & & O4-Ca1-O9 & $75.23(7)$ \\
\hline & & O9-Ca1-O5 & $115.19(8)$ \\
\hline & & O9-Ca1-O8 & $72.48(7)$ \\
\hline & & O10-Ca1-O9 & $72.82(7)$ \\
\hline & & O9-Ca1-O12 & $139.61(7)$ \\
\hline & & O9-Ca1-O11 & $140.40(7)$ \\
\hline & & O10-Ca1-O3 & $81.34(6)$ \\
\hline & & O4-Ca1-O10 & $126.59(6)$ \\
\hline & & O10-Ca1-O8 & $125.41(7)$ \\
\hline & & O12-Ca1-O3 & $70.07(7)$ \\
\hline & & O12-Ca1-O4 & $109.42(7)$ \\
\hline & & O12-Ca1-O5 & $79.15(7)$ \\
\hline & & O8-Ca1-O12 & $147.11(7)$ \\
\hline & & O12-Ca1-O10 & $73.21(7)$ \\
\hline & & O12-Ca1-O11 & $76.71(7)$ \\
\hline & & O11-Ca1-O3 & $101.68(6)$ \\
\hline & & O11-Ca1-O4 & $77.09(6)$ \\
\hline & & O11-Ca1-O8 & $76.14(7)$ \\
\hline & & O11-Ca1-O10 & $146.65(6)$ \\
\hline
\end{tabular}

Table 3. Catalytic performance of the $\mathrm{Ca}$ (II) complex in the oxidation of benzyl alcohol

\begin{tabular}{clccc}
\hline Entry & Solvent & Temperature $\left({ }^{\circ} \mathrm{C}\right)$ & Conversion $(\%)$ & Selectivity $(\%)$ \\
\hline 1 & 1,4-dioxane & 130 & 78 & 98 \\
2 & tetrahydrofuran & 130 & 57 & 61 \\
3 & dimethylformamide & 130 & 12 & 25 \\
4 & acetonitrile & 130 & 10 & 14 \\
5 & ethyl acetate & 130 & 9 & 14 \\
6 & 120 & 6 & 98 \\
7 & 1,4-dioxane & 140 & 80 & 67 \\
\hline
\end{tabular}


$\mathrm{Ca}(\mathrm{II})$ coordination polymer catalyst was supposed. First the hydroxyl group in benzyl alcohol can coordinate with coordinatively unsaturated calcium sites to obtain the intermediate calcium-alcoholate species. And the proton in the hydroxyl group is abstracted to the support to form surface adsorbed $\mathrm{H}$ species and alkoxide intermediates. Then the alkoxide intermediates undergo a $\beta$-hybride elimination to give the target product benzaldehyde. At the same time, Ca-hydride species is created that is then oxidized by the $\mathrm{O}_{2}$, which ultimately regenerated the original $\mathrm{Ca}(\mathrm{II})$ coordination polymer with releasing of $\mathrm{H}_{2} \mathrm{O}$ and $\mathrm{O}_{2}$.

\section{Conclusions}

We have synthesized a new calcium(II) complex by one-pot method. Its structure was determined by elemental analysis, IR and single crystal X-ray diffraction. The results of catalytic activity show that the calcium (II) complex exhibits good catalytic activity for oxidation of benzylic alcohol with the conversion of benzyl alcohol and selectivity of benzaldehyde in 1,4-dioxane are $78 \%$ and $98 \%$, respectively.

\section{Acknowledgements}

This project was supported by the National Natural Science Foundation of China (No. 21171132), the National Natural Science Foundation of Shandong (ZR2014BL003), the Project of Shandong Province Higher Educational Science and Technology Program (J14LC01), and Science Foundation of Weifang.

\section{References}

[1] Huang, Y.B., Liang, J., Wang, X.S., Cao, R. (2017). Multifunctional Metal-Organic Framework Catalysts: Synergistic Catalysis and Tandem Reactions. Chemical Society Reviews, 46: 126-157.

[2] Han, H.L., Liu, Y., Liu, J.Y., Nomura, K., Lia, Y.S. (2013). Synthesis of Binuclear Phenoxyimino Organoaluminum Complexes and Their Use as The Catalyst Precursors for Efficient Ring-Opening Polymerisation of $\varepsilon$ Caprolactone. Dalton Transactions, 42: 12346-12353.

[3] Chai, Z., Wang, Y.M., Tang, M.J., Mu, X.L., Hou, J.S., Yang, G.S. (2017). Chiral RareEarth Metal Complexes with a Tridentate Amido-Fluorenyl Ligand: Syntheses, structures and Catalytic Performance. Journal of Organometallic Chemistry, 846: 236-241.
[4] Li, B., leng, K., Zhang, Y., Dynes, J.J., Wang, J., Hu, Y., Ma, D., Shi, Z., Zhu, L., Zhang, D., Sun, Y., Chrzanowski, M., Ma, S. (2015). Metal-Organic Framework based Upon the Synergy of a Brönsted Acid Framework and Lewis Acid Centers as a Highly Efficient Heterogeneous Catalyst for Fixed-bed Reactions. Journal of the American Chemical Society, 137: 4243-4248.

[5] Kim, J., Kim, S.N., Jang, H.G., Seo, G., Ahn, W.S. (2013). $\mathrm{CO}_{2}$ Cycloaddition of Styrene Oxide Over MOF Catalysts. Applied Catalysis A, 453: 175-180.

[6] Yang, G., Schaffner, B., Blug, M., Hensen, E.J.M., Pidko, E.A. (2014). A Mechanistic Study of Ni-catalyzed Carbon Dioxide Coupling with Ethylene towards the Acrylic Acid Manufacture. Chem CatChem., 6: 800-807.

[7] Liu, L.L., Yu, C.X., Zhou, W., Zhang, Q.G., Liu, S.M., Shi, Y.F. (2016). Construction of Four Zn(II) Coordination Polymers Used as Catalysts for the Photodegradation of Organic Dyes in Water. Polymers, 8: 3.

[8] Wang, L.H., Liang, L., Li, P.F. (2017). Synthesis, Crystal Structure, Catalytic Properties, and Luminescent of a Novel Eu(III) Complex Material with 4-Imidazolecarboxaldehyde-pyridine-2-carbohydrazone. Bulletin of Chemical Reaction Engineering \& Catalysis, 12:185-190.

[9] Wang, L.H., Liang, L., Wang, X. (2017). Synthesis, Structural Characterization and Catalytic Activity of $\mathrm{A} \mathrm{Cu}(\mathrm{II})$ Coordination Polymer Constructed from 1,4-Phenylenediacetic Acid and 2,2'-Bipyridine. Bulletin of Chemical Reaction Engineering \& Catalysis, 12: 113118.

[10] Beyzavi, M.H., Vermeulen, N.A., Howarth, A.J., Tussupbayev, S., League, A.B., Schweitzer, N.M., Gallagher, J.R., Platero-Prats, A.E., Hafezi, N., Sarjeant, A.A., Miller, J.T., Chapman, K.W., Stoddart, J.F., Carmer, C.J., Hupp, J.T., Farha, O.K. (2015). A HafniumBased Metal-Organic Framework as a Nature-Inspired Tandem Reaction Catalyst. Journal of the American Chemical Society, 137: 13624-13631.

[11] Song, F., Wang, C., Falkowski, J.M., Ma, L., Lin, W. (2010). Isoreticular Chiral Metal-Organic Frameworks for Asymmetric Alkene Epoxidation: Tuning Catalytic Activity by Controlling Framework Catenation and Varying Open Channel Sizes. Journal of the American Chemical Society, 132: 1539015398.

[12] Xiong, J., Zhang, J.J., Sun, Y.Y., Dai, Z.R., Pan, X.B., Wu, J.C. (2015). Iso-Selective RingOpening Polymerization of Rac-Lactide Cata- 
lyzed by Crown Ether Complexes of Sodium and Potassium Naphthalenolates. Inorganic Chemistry, 54: 1737-1743.

[13] Vermoortele, F., Ameloot, R., Vimont, A., Serre, C., Vos, D.D. (2011). An Amino-Modified Zr-Terephthalate Metal-Organic Framework as an Acid-Base Catalyst for Cross-Aldol Condensation. Chemical Communications, 47: 1521-1523.

[14] Dau, P.V., Cohen, S.M. (2015). A Bifunctional, Site-Isolated Metal-Organic FrameworkBased Tandem Catalyst. Inorganic Chemistry, 54: 3134-3138.

[15] Yang, Y., Yao, H.F., Xi, F.G., Gao, E.Q. (2014). Amino-Functionalized Zr(IV) MetalOrganic Framework as Bifunctional AcidBase Catalyst for Knoevenagel Condensation. Journal of Molecular Catalysis A: Chemical, 390: 198-205.

[16] Rasero-Almansa, A.M., Corma, A., Iglesias, M., Sanchez, F. (2014). Design of a Bifunctional Ir-Zr Based Metal-Organic Framework Heterogeneous Catalyst for the N-Alkylation of Amines with Alcohols. ChemCatChem, 6: 1794-1800.

[17] Gascon, J., Aktay, U., Hernandezalonso, M., Vanklink, G., Kapteijn, F. (2009). AminoBased Metal-Organic Frameworks as Stable, Highly Active Basic Catalysts. Journal of Catalysis, 261: 75-87.

[18] Wu, P., Wang, J., Li, Y., He, C., Xie, Z., Duan, C. (2011). Luminescent Sensing and Catalytic Performances of a Multifunctional Lanthanide-Organic Framework Comprising a Triphenylamine Moiety. Advanced Functional Materials, 21: 2788-2794.

[19] Valvekens, P., Vandichel, M., Waroquier, M., Speybroeck, V.V., Vos, D.D. (2014). MetalDioxidoterephthalate MOFs of the MOF-74 Type: Microporous Basic Catalysts with WellDefined Active Sites. Journal of Catalysis, 317: 1-10.

[20] Sierra, M.P., Rasero-Almansa, A.M., Corma, A., Felix-Sanchez, M.I. (2013). Bifunctional Iridium-(2-aminoterephthalate) - Zr-MOF Chemoselective Catalyst for the Synthesis of Secondary Amines by One-Pot Three-Step cascade Reaction. Journal of Catalysis, 299: 137-145.

[21] Cai, J., Lu, J.Y., Chen, Q.Y., Qu, L.L., Lu, Y.Q., Gao, G.F. (2014). Eu-Based MOF/graphene Oxide Composite: a Novel Photocatalyst for the Oxidation of Benzyl Alcohol Using Water as Oxygen Source. New Journal of Chemistry, 41: 3882-3886.
[22] Tan, T.H., Scott, J., Ng, Y.H., Taylor, R.A., Aguey-zinsou, K.F., Amal, R. (2016). C-C Cleavage by $\mathrm{Au} / \mathrm{TiO}_{2}$ During Ethanol Oxidation: Understanding Bandgap Photoexcitation and Plasmonically Mediated Charge Transfer via Quantitative in situ Drifts. ACS Catalysis, 6: 8021-8029.

[23] Zhou, H., Xiao, L.P., Liu, X.N., Li, S., Kobayashi, H., Zheng, X.M., Fan, J. (2012). Defectless, Layered Organo-titanosilicate with Superhydrophobicity and Its Catalytic Activity in Room-temperature Olefin Epoxidation. Chemical Communications, 55: 6954-6956.

[24] Tai, X.S., Liu, L.L., Yin, J. (2014). Synthesis, Crystal Structure of Tetra-Nuclear Macrocyclic $\mathrm{Cu}$ (II) Complex Material and Its Application as Catalysts for $\mathrm{A}^{3}$ Coupling Reaction. Journal of Inorganic and Organometallic Polymers and Materials, 24: 1014 -1020.

[25] Wang, L.H., Wang, X., Tai, X.S. (2017). Synthesis, Crystal Structure and Catalytic Activity of a 1D Chained Ca(II) Coordination Polymer with 3,5-Bis(4-pyridylmethoxy)benzoate Ligand. Crystals, 7: 72.

[26] Tai, X.S., Li, P.F., Wang, X., Liu, L.L. (2017). Synthesis, Structural Characterization, and Catalytic Property of A Zn(II) Complex with 5-Bromosalicylaldehyde Ligand. Bulletin of Chemical Reaction Engineering \& Catalysis, 12: 364-369.

[27] Tai, X.S., Guo, Q.Q., Li, P.F., Liu, L.L. (2018). A Ca(II) Coordination Polymer of 2-Carboxybenzaldehyde: Synthesis, Crystal Structure, and Catalytic Activity in Oxidation of Benzyl Alcohol. Crystals, 8: 150.

[28] Sheldrick, G.M. (1997). SHELXL-97, Program for Crystal Structure Solution. University of Göttingen: Göttingen, Germany.

[29] Sheldrick, G.M. (2015). SHELXT-Integrated space-group and crystal-structure determination. Acta Crystallographica, C71: 3-8.

[30] Tai, X.S., Wang, X. (2015). Synthesis and Crystal Structure of a 1D Chained Coordination Polymer Constructed from $\mathrm{Ca}^{2+}$ and 2-[(E)-(2-Furoylhydrazono) methyl]benzene sulfonate. Crystals, 5: 458-465. 